\title{
Evaluating Dihydroazulene/Vinylheptafulvene Photoswitches for Solar Energy Storage Applications
}

\author{
Zhihang Wang, ${ }^{[a]}$ Jonas Udmark, ${ }^{[\mathrm{b}]}$ Karl Börjesson, ${ }^{[c]}$ Rita Rodrigues, ${ }^{[\mathrm{a}]}$ Anna Roffey, ${ }_{r}^{[\mathrm{a}]}$ \\ Maria Abrahamsson, ${ }^{[a]}$ Mogens Brøndsted Nielsen, ${ }^{*[b]}$ and Kasper Moth-Poulsen ${ }^{*[a]}$
}

\begin{abstract}
Efficient solar energy storage is a key challenge in striving toward a sustainable future. For this reason, molecules capable of solar energy storage and release through valence isomerization, for so-called molecular solar thermal energy storage (MOST), have been investigated. Energy storage by photoconversion of the dihydroazulene/vinylheptafulvene (DHA/VHF) photothermal couple has been evaluated. The robust nature of this system is determined through multiple energy storage and release cycles at elevated temperatures in three different solvents. In a nonpolar solvent such as toluene, the DHA/VHF system can be cycled more than 70 times with less than $0.01 \%$
\end{abstract}

degradation per cycle. Moreover, the $\left[\mathrm{Cu}\left(\mathrm{CH}_{3} \mathrm{CN}\right)_{4}\right] \mathrm{PF}_{6}$-catalyzed conversion of VHF into DHA was demonstrated in a flow reactor. The performance of the DHA/VHF couple was also evaluated in prototype photoconversion devices, both in the laboratory by using a flow chip under simulated sunlight and under outdoor conditions by using a parabolic mirror. Device experiments demonstrated a solar energy storage efficiency of up to $0.13 \%$ in the chip device and up to $0.02 \%$ in the parabolic collector. Avenues for future improvements and optimization of the system are also discussed.

\section{Introduction}

The rise in energy demands as a consequence of fast economic growth and an increasing global population poses challenges for future generations. In 2050, energy consumption is projected to be $27.6 \mathrm{TW}$, twice that of $2001 .^{[1]}$ At the same time, associated environmental challenges render the use of fossil fuels less desirable. Consequently, development of sustainable resources has become a focus of research during recent decades. ${ }^{[2]}$ As the most abundant energy source on Earth, solar energy utilization has seen a rapid expansion with more than $900 \%$ increase of installed capacity between 2009 and 2015, including both utility-scale solar power plants and distributed photovoltaics, ${ }^{[3]}$ as well as solar water heating for domestic and industrial applications. ${ }^{[4]}$ As solar energy production is

[a] Z. Wang, Dr. R. Rodrigues, Dr. A. Roffey, Dr. M. Abrahamsson,

Prof. Dr. K. Moth-Poulsen

Department of Chemistry and Chemical Engineering

Chalmers University of Technology, Gothenburg (Sweden)

E-mail: kasper.moth-poulsen@chalmers.se

[b] J. Udmark, Prof. Dr. M. B. Nielsen

Department of Chemistry, University of Copenhagen

Universitetsparken 5, 2100 Copenhagen (Denmark)

E-mail:mbn@chem.ku.dk

[c] Dr. K. Börjesson

Department of Chemistry and Molecular Biology, University of Gothenburg Kemigården 4, 41296 Gothenburg (Sweden)

$\square$ Supporting Information and the ORCID identification number(s) for the

(i) author(s) of this article can be found under https://doi.org/10.1002/ cssc. 201700679.

of (c) 2017 The Authors. Published by Wiley-VCH Verlag GmbH \& Co. KGaA. This is an open access article under the terms of the Creative Commons Attribution-NonCommercial License, which permits use, distribution and reproduction in any medium, provided the original work is properly cited and is not used for commercial purposes.

being widely implemented, challenges associated with time variations in solar energy output and variations in energy consumption lead to an increased need for efficient, scalable solar energy storage technologies.

One possible means for facilitating this need is through socalled molecular solar thermal energy storage (MOST) systems. ${ }^{[5]}$ A MOST system is based on a molecule that, upon exposure to sunlight, can be photoisomerized into a high-energy, metastable isomer. When required, the energy stored in the chemical bonds can be released by thermally or catalytically triggering back-conversion into the parent compound, thereby releasing the stored energy as heat. The requirements for such a system have been discussed in detail previously. ${ }^{[6]}$ In essence, an ideal MOST system should have a long lifetime under ambient conditions, high photoisomerization quantum yield, large spectral overlap with the solar spectrum, and sufficiently high energy of the metastable isomer. Furthermore, it should be highly robust and thus able to undergo multiple cycles without significant loss of capabilities through degradation.

Several types of photoswitches for MOST applications have been investigated, including functionalized norbornadienes, $^{[5 a, 6 a, b]}$ fulvalene-diruthenium derivatives, ${ }^{[2,7]}$ azobenzenes, $^{[6 c, 8]}$ azopolymers, ${ }^{[9]}$ and several dihydroazulene/vinylheptafulvene (DHA/VHF) derivatives. ${ }^{[10]}$ The latter system, which is shown in Scheme 1 (DHA1/VHF1), is the subject of the present work. DHA1 can be converted into its corresponding highenergy isomer VHF1 by a photoinduced ring-opening reaction. However, VHF can only undergo a thermal back reaction to the DHA form. Therefore, it should be possible to have full conversion between the two states in both directions. VHF1 itself exists in an equilibrium between s-cis and s-trans con- 


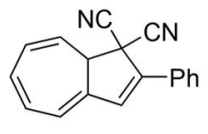

DHA1

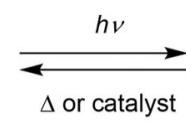<smiles>C1CCCCC1</smiles><smiles></smiles>

VHF1 (s-cis)<smiles>N#CC(C#N)=C(/C=C/c1ccccc1)c1ccccc1</smiles>

VHF1 (s-trans)

Scheme 1. The dihydroazulene (DHA1)/vinylheptafulvene (VHF1)-based molecular sola thermal energy storage (MOST) system examined in this study.

formers; the s-trans conformer usually being the more stable of the two, whereas s-cis is the conformation necessary for ring closure. The combination of a large spectral difference between DHA and VHF and a high enthalpy of the photoreaction of $35.2 \mathrm{~kJ} \mathrm{~mol}^{-1}$ (correspond to $0.14 \mathrm{MJ} \mathrm{kg}^{-1}$ calculated in vacuum, and $0.13 \mathrm{~J} \mathrm{~cm}^{-3}$ assuming a volumetric mass density of DHA of $\left.0.9 \mathrm{~g} \mathrm{~cm}^{-3}\right)^{[10 b]}$ fulfills several of the requirements preferred for a MOST system. ${ }^{[5]}$ In addition, many DHA derivatives have been made, where the lifetimes can be prolonged for the corresponding VHFs. ${ }^{[1]}$ Moreover, the synthesis of DHA1 employs readily available starting materials and has been accomplished on a large (15 g) scale. ${ }^{[12]}$

Herein, we investigate the DHA/VHF couple as a possible candidate in a MOST device. As a part of this study, we have assessed both solubility and stability of this system by subjecting DHA/VHF to multiple photothermal energy storage and release cycles. In addition, we test the conversion of the MOST system both in laboratory scale devices (ca. $5 \mathrm{~cm}^{2}$ ) using artificial sun, as well as in larger scale (ca. $900 \mathrm{~cm}^{2}$ irradiated area) devices under natural sunlight, outdoor conditions. This is, to our knowledge, the first attempt to bring the MOST system out of the lab, demonstrating one possible avenue for future lab-to-site transfer. Importantly, this experiment verifies that DHA can be photochemically converted both under simulated conditions and under natural outdoor conditions. The experiments are accompanied by a discussion seeking to identify where future optimization of the DHA/ VHF couple should be focused.

\section{Results and Discussion}

An important feature of a MOST system is its ability to absorb photons efficiently, store the energy for extended periods of time, and recover the energy upon thermal back-conversion. These processes should ideally proceed without degradation. Figure 1 shows the absorption spectra of DHA1 dissolved in toluene after exposure to an increasing amount of light, showing clear isosbestic points, and thus a clean conversion into VHF1. The robustness of the system may vary in different solvents, and the rate of the thermal back-conversion of VHF to DHA is known to be very solvent dependent; being faster in more polar solvents. ${ }^{[12]}$ Three candidate solvents were selected for testing in order to cover a range of important solvent characteristics; namely, toluene (nonpolar), acetonitrile (polar aprotic), and ethanol (polar protic). The solubility of the molecules is also a critical parameter, since together with the energy density of the pure compounds it determines the maximal adiabatic temperature gradient one can expect to achieve upon heat release. ${ }^{[6]}$ The solubility of DHA1 in the three studied solvents was measured according to a slightly modified literature procedure ${ }^{[13]}$ (see the Supporting Information, section I for details; results summarized in Table 1). Clearly, an increase in the solubility of pure DHA1 correlates with decreasing polarity of the solvent, and it has a solubility of $0.2 \mathrm{M}$ in

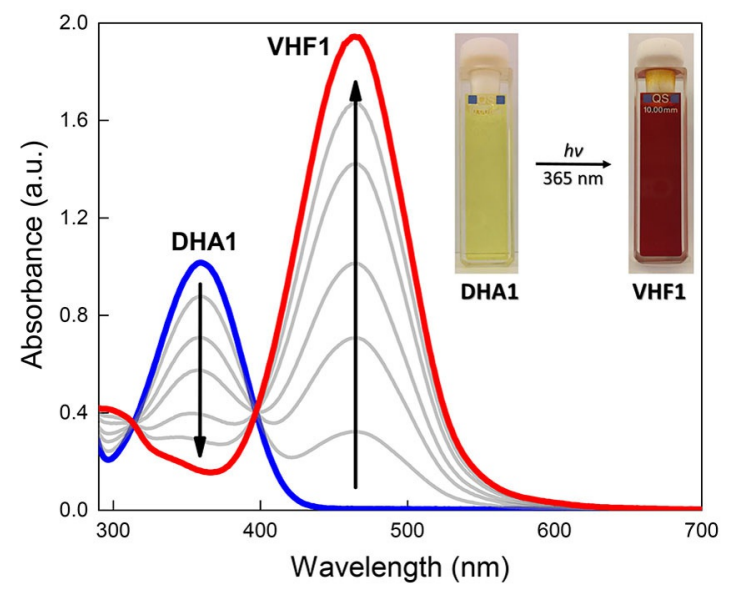

Figure 1. Absorption spectra of DHA1 (in blue) and its photoisomer VHF1 (in red); inset shows color change of the compound in toluene before and after irradiation with $\lambda=365 \mathrm{~nm}$ light.

\begin{tabular}{l} 
Table 1. Summary of physical properties of DHA1 in different solvents. \\
\begin{tabular}{lllll} 
Solvent & $\begin{array}{l}\text { Photoisomerization } \\
\text { quantum yield }{ }^{[14]}\end{array}$ & $\begin{array}{l}\text { Thermally induced back- } \\
\text { conversion half-life at } \\
25^{\circ} \mathrm{C}[\mathrm{min}]^{[12]}\end{array}$ & $\begin{array}{l}\text { Solubility } \\
{\left[\mathrm{mg} \mathrm{mL}^{-1}\right]}\end{array}$ & $\begin{array}{l}\text { Degradation } \\
{[\% \text { loss per }} \\
\text { cycle] }\end{array}$ \\
\hline $\begin{array}{l}\text { toluene } \\
\text { acetonitrile } \\
\text { ethanol }\end{array}$ & 0.6 & 1474 & 55 & 0.01 \\
& 0.5 & 218 & 36 & 0.18 \\
\end{tabular} \\
\hline
\end{tabular}

toluene. A low-polarity solvent such as toluene, therefore, could combine a large energy density (high solubility of DHA) with a long, sustained release of the stored energy (slower back-conversion of VHF).

\section{Cyclability test}

The robustness of the DHA1/VHF1 couple was probed by subjecting solutions of the photoswitch to as many as 70 complete photothermal cycles. The characteristic absorbance of VHF1 at $\lambda=460 \mathrm{~nm}$ was used to follow both processes, revealing a remarkable stability, with less than $0.01 \%$ degradation per cycle in toluene. It also demonstrates that DHA1 degrades faster in polar solvents with around $0.28 \%$ and $0.18 \%$ loss of molecules per cycle for ethanol and acetonitrile, respectively (Figure 2).

The ethanol and acetonitrile solutions were analyzed by LCMS after the cycling tests. Many components could be seen, 


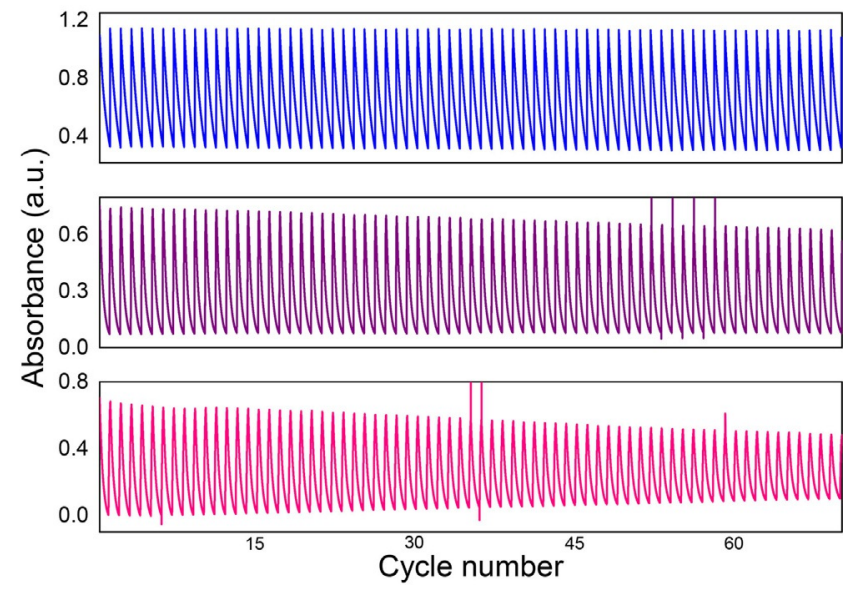

Figure 2. Cyclability test based on absorbance at $\lambda=460 \mathrm{~nm}$ in toluene (blue, ca. $10^{-4} \mathrm{M}$ ), acetonitrile (purple, ca. $10^{-4} \mathrm{M}$ ) and ethanol (red, ca. $10^{-4} \mathrm{M}$ ). To reduce the back-conversion time, the experiments were performed at a constant temperature of $60^{\circ} \mathrm{C}$. Light at $\lambda=365 \mathrm{~nm}$ was repeatedly switched on and off. One cycle corresponds to one light-on period and one light-off period. A total of 70 cycles are shown. The baseline absorption increase for the ethanol sample is attributed to the formation of azulene. Parasitic signals (spikes) appear in acetonitrile and ethanol samples due to instrumental fluctuations.

and two of these seem to be azulenes resulting from either elimination of HCN from DHA1 or a substitution reaction (presumably $\mathrm{S}_{\mathrm{N}} 2^{\prime}$ ) through nucleophilic attack by EtOH followed by an oxidation (Figure 3 ) in accordance with previous observations. $^{[15]}$

\section{Catalytic conversion of VHF1 to DHA1 in flow reactor}

With a view to triggering the energy release on demand, we recently found that the rate of the back-reaction from VHF1 to DHA1 can be significantly enhanced by $\mathrm{Cu}^{\prime}$ ions. ${ }^{[10 e]}$ Thus, for<smiles></smiles>

$\left[\mathrm{M}+\mathrm{H}^{+}\right]: \quad m / z=230$<smiles></smiles>

$\left[\mathrm{M}+\mathrm{H}^{+}\right]: m / z=274$

Figure 3. Possible degradation products based on mass spectrometry analysis.

VHF1 we found a decrease in the half-life from $545 \mathrm{~min}$ at $25^{\circ} \mathrm{C}$ in dichloromethane to $18-22 \mathrm{~min}$ upon addition of 1 equivalent of $\left[\mathrm{Cu}\left(\mathrm{CH}_{3} \mathrm{CN}\right)_{4}\right] \mathrm{BF}_{4}$. Here, we demonstrate that the catalyzed reaction can be carried out under flow conditions by using a $\mathrm{Cu}^{\prime}$ salt in a fixed-bed flow reactor. First, a DHA1 solution (ca. $1.7 \times 10^{-3} \mathrm{M}$ ) in toluene was fully converted into VHF1 by using a solar simulator lamp for $1 \mathrm{~h}$. A flow reactor was constructed from Teflon tubing and packed with solid $\left[\mathrm{Cu}\left(\mathrm{CH}_{3} \mathrm{CN}\right)_{4}\right] \mathrm{PF}_{6}$ crystals. A flow speed of $5 \mathrm{~mL} \mathrm{~h}^{-1}$ was selected to back-convert VHF1 into its isomer. Up to $81.3 \%$ of VHF1 was converted into DHA1 (see Figure 4 and Experimental Section for details).

\section{Indoor microfluidic chip device}

For energy storage applications, the ability of the DHA1/VHF1 couple to store energy is of prime importance. Calculations show a Gibbs free energy difference between DHA1 and VHF1 of $27.7 \mathrm{~kJ} \mathrm{~mol}^{-1}$ and an enthalpy difference $\left(\Delta H_{\text {stor }}\right)$ of $35.2 \mathrm{~kJ} \mathrm{~mol}^{-1} . \Delta H_{\text {stor }}$ values were used in the estimation of the solar energy storage efficiency $\eta_{\text {MOST }}$ [as determined by Equations (1)-(3); see below]. ${ }^{[10 b, 16]}$ From the point of view of molecular stability, toluene, or a similar nonpolar solvent, seems to be the most attractive choice for device testing, because of its long VHF half-life, high quantum yield, high solubility, and

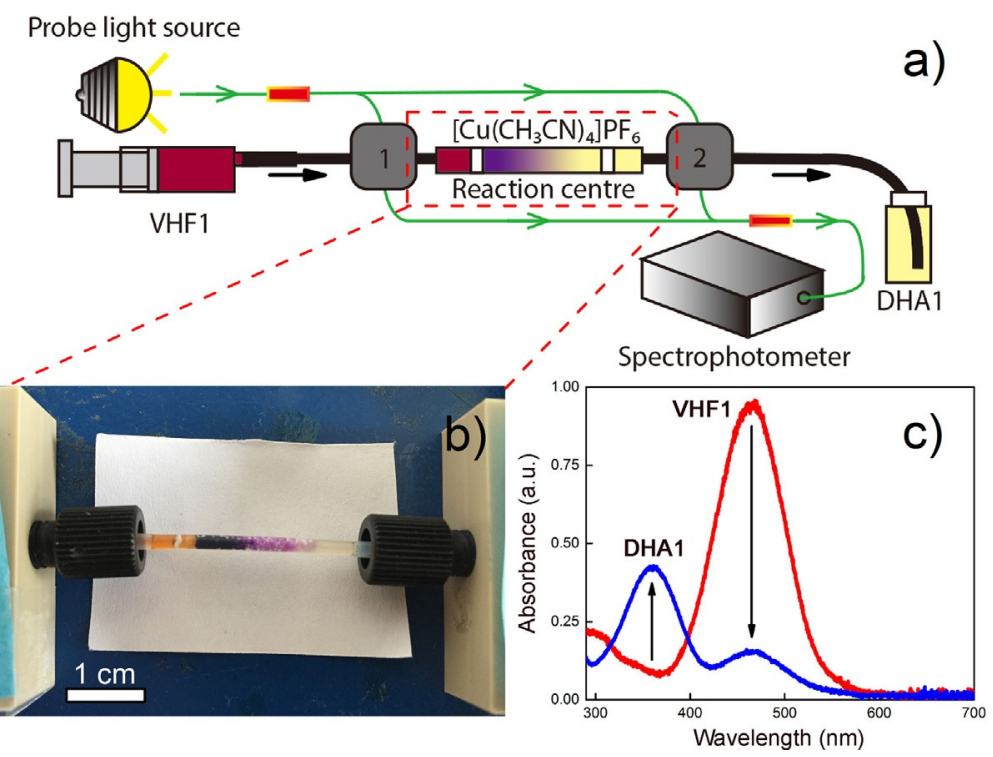

Figure 4. Catalytic conversion in flow reactor: $a$, b) Scheme and photograph of the back-conversion setup. Boxes 1 and 2 contain in-line UV/Vis spectrometers. c) UV/Vis spectra before (red) and after (blue) exposure to $\left[\mathrm{Cu}\left(\mathrm{CH}_{3} \mathrm{CN}\right)_{4}\right] \mathrm{PF}_{6}$. 
minimal degradation. Thus, toluene was employed in the device testing experiments.

To evaluate the basic function of the DHA1/VHF1 MOST system under continuous-flow irradiation conditions, a microfluidic reactor was built to test the conversion ratio of DHA1 into VHF1. Conversion was tested at two different concentrations in toluene by using simulated sunlight ( 1 sun, AM1.5). Solutions of DHA1 at $1 \times 10^{-3} \mathrm{M}$ and $4 \times 10^{-3} \mathrm{M}$ were pumped through a $85 \mu \mathrm{m}$ optical path-length microfluidic chip, and the conversion was determined by monitoring the UV/Vis absorption using two flow-cell spectrometers positioned before and after irradiation (Figure 5).
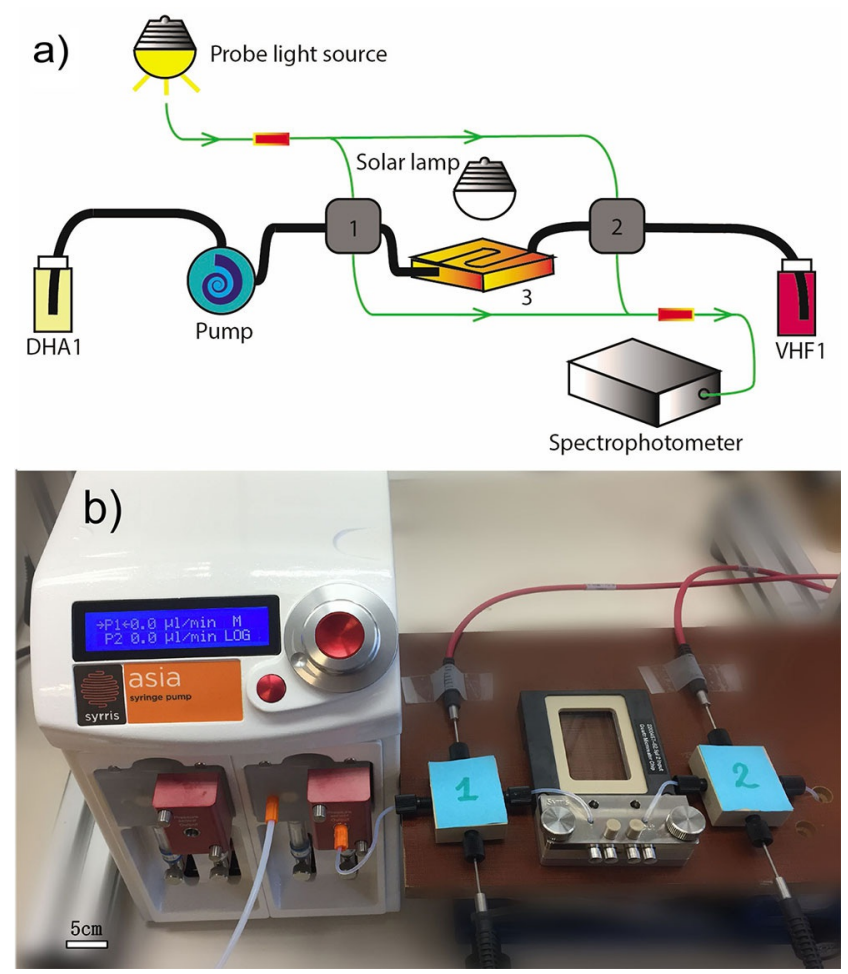

Figure 5. a) Microfluidic chip test setup. Boxes 1 and 2 contain in-line UV/Vis spectrometers and box 3 contains the microfluidic chip. Green line shows optical waveguides containing split and combined probe light. b) Picture of the used setup.

The capacity of a MOST system to store energy can be characterized by $\eta_{\text {MOsT. }}$ Intuitively, the theoretical maximum of the energy storage limit is a function of the absorption overlap with the solar spectrum, concentration, photoisomerization quantum yield $\left(\phi_{\text {iso }}\right)$, and energy difference between the two isomers $\left(\Delta H_{\text {stor }}\right)$. The theoretical capacity is expressed in Equation (1):

$\eta_{\text {MOST }}=\frac{\int_{0}^{\lambda_{\text {onset }}} \frac{E_{\text {AM1.5 }}(\lambda)(1-T) \phi_{\text {iso }} \Delta H_{\text {stor }}}{h \nu N_{\mathrm{A}}} \mathrm{d} \lambda}{\int E_{\mathrm{AM} 1.5}(\lambda) \mathrm{d} \lambda} \times 100 \%$

where $E_{\mathrm{AM} 1.5}(\lambda)$ is the spectral irradiance (energy current density) in $\mathrm{J} \mathrm{s}^{-1} \mathrm{~m}^{-2} \mathrm{~nm}^{-1} ; T$ is the transmittance of DHA in specified device; $h$ is the Plank constant in $\mathrm{J} s ; v$ is the frequency of incoming light in $\mathrm{s}^{-1}$; and $N_{\mathrm{A}}$ is Avogadro's constant. The photoisomerization quantum yield is defined as in Equation (2):

$\phi_{\text {iso }}=\frac{\text { number of isomerization events }}{\text { number of photons absorbed }}$

Based on idealized conditions, that is, neglecting reflection losses, the calculated maximum energy storage efficiency is $0.61 \%$ for a saturated solution of DHA1 in toluene. Thus the maximum efficiencies for the two solutions investigated in the device could be at most $0.13 \%$ at $4 \times 10^{-3} \mathrm{M}$ and $0.04 \%$ at $1 \times$ $10^{-3} \mathrm{M}$ (Figure $6 \mathrm{a}$ ). The experimental energy storage efficiency is calculated using Equation (3):

$\eta_{\mathrm{MOST}}=\frac{\dot{n}_{\mathrm{DHA}} \alpha_{\mathrm{VHF}} \Delta H_{\mathrm{stor}}}{A E_{\mathrm{AM} 1.5}}$

where $\dot{n}_{\mathrm{DHA}}$ is the DHA1 flow speed in mols ${ }^{-1}, \alpha_{\mathrm{VHF}}$ is the conversion ratio of DHA1 into VHF1 and $A$ is the irradiated area in $\mathrm{m}^{2}$.
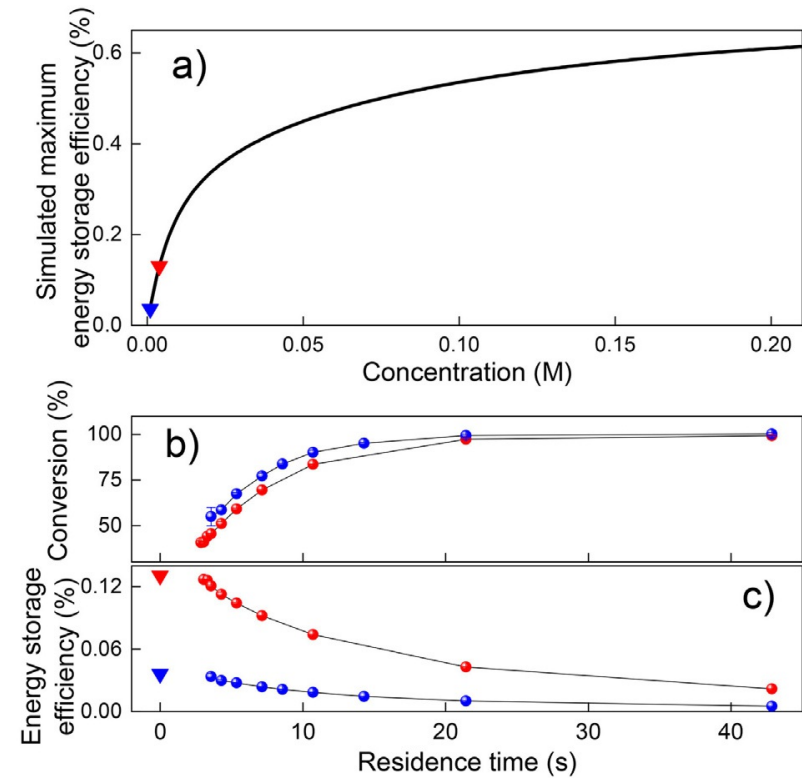

Figure 6. a) Simulated maximum energy storage efficiency as a function of DHA concentration through a $85 \mu \mathrm{m}$ path-length device. The maximum concentration $(0.21 \mathrm{M})$ corresponds to DHA1's maximum solubility in toluene. Red and blue triangles correspond to the concentrations of DHA1 used experimentally, $4 \times 10^{-3} \mathrm{M}$ and $1 \times 10^{-1} \mathrm{M}$, respectively. b, c) Conversion percentage and evolution of the energy storage efficiency as a function of residence time in the microfluidic chip for these solutions (average taken from three separate measurements). In (c), red and blue triangles correspond to the calculated value from (a)

Experimentally, by controlling the flow speed, different fluid residence times were obtained ranging from $3 \mathrm{~s}$ to $43 \mathrm{~s}$. The variation in residence time increased the conversion percentage of DHA1 into VHF1 from around $40 \%$ to a complete transformation for both used concentrations (Figure $6 \mathrm{~b}$ ). Interestingly, an irradiation of 10 seconds resulted in about $80 \%$ 
conversion in both cases. The maximum measured energy storage efficiency in the microfluidic chip was found to be $0.13 \%$ at $4 \times 10^{-3} \mathrm{M}$ and $0.034 \%$ at $1 \times 10^{-3} \mathrm{M}$, at a residence time of $3 \mathrm{~s}$, which are close to the theoretical limits (Figure $6 \mathrm{c}$ ). To put these numbers in context, solar energy conversion efficiencies have been reported under similar conditions for ruthenium fulvalene $\left(\mathrm{Ru}_{2} \mathrm{Fv}\right)$ compounds $(0.0071 \%)$ mainly limited by a poor quantum yield and norbornadienes (up to $1.1 \%)_{1}^{[2,17]}$ limited by quantum yield and onset of absorption.

An ideal MOST candidate molecule should show a quasiconstant efficiency at different concentrations and long residence times. Ideally, the metastable isomer should not absorb light in the solar spectrum. However, the energy storage efficiency decreases with longer residence times in the chip. This behavior is caused by an inner filter effect due to VHF absorbing light in the visible and UV range of the solar spectrum, thus parasitizing on the incoming solar energy necessary for the photoconversion of DHA1 into VHF1.

\section{Outdoor parabolic concentrator}

In order to demonstrate the function of the system under real outdoor conditions, a parabolic concentrator combined with a solar tracker was constructed for outdoor testing. This device also works as a proof-of-principle experiment toward future lab-to-site transfer. Sun light was focused on an apparatus consisting of jacketed glass tubing (Figure 7). ${ }^{[6 a]}$ The inner tube serves as a channel for cooling water to avoid back-conversion caused by an increased temperature from the focusing light. The DHA1 solution was pumped through the $5.8 \mathrm{~mL}$ outer jacket to maximize the direct exposure to sunlight. Importantly, this heating of the water can be exploited as an auxiliary product in hybrid water heating/MOST devices, as we recently reported. ${ }^{[17]}$

In this case, a saturated solution of DHA1 can give a theoretical limit storage efficiency of $0.65 \%$ in toluene. For this experiment, a $3.7 \times 10^{-3} \mathrm{M}$ toluene solution of DHA1 was pumped through the system at variable residence times, ranging from $35 \mathrm{~s}$ to $417 \mathrm{~s}$ (ca. 600 to $50 \mathrm{~mL} \mathrm{~h}^{-1}$ ), giving conversion percentages from $84 \%$ up to $100 \%$. However, estimation of the efficiency by using Equation (3) and assuming that the solar flux was the standard AM1.5, the measured maximum energy storage efficiency was only $0.02 \%$, which is far from the theoretical maximum of $0.45 \%$ (Figure 8 ). Since the microfluidic device gave a good match between calculated and measured efficiencies, we accredit the majority of the large discrepancy found in the scaled-up device to a much larger device volume and a longer path length consequently amplifying the inner filter effects from competition of absorption between DHA1 and VHF1, as well as a lower actual solar influx than the standard AM1.5 and minor misalignment of the concentrator. Future device and molecular designs should take the challenge with inner filter effects into account by having shorter path lengths, redshifting the strong VHF absorbance or lower spectroscopic overlap between the isomers.
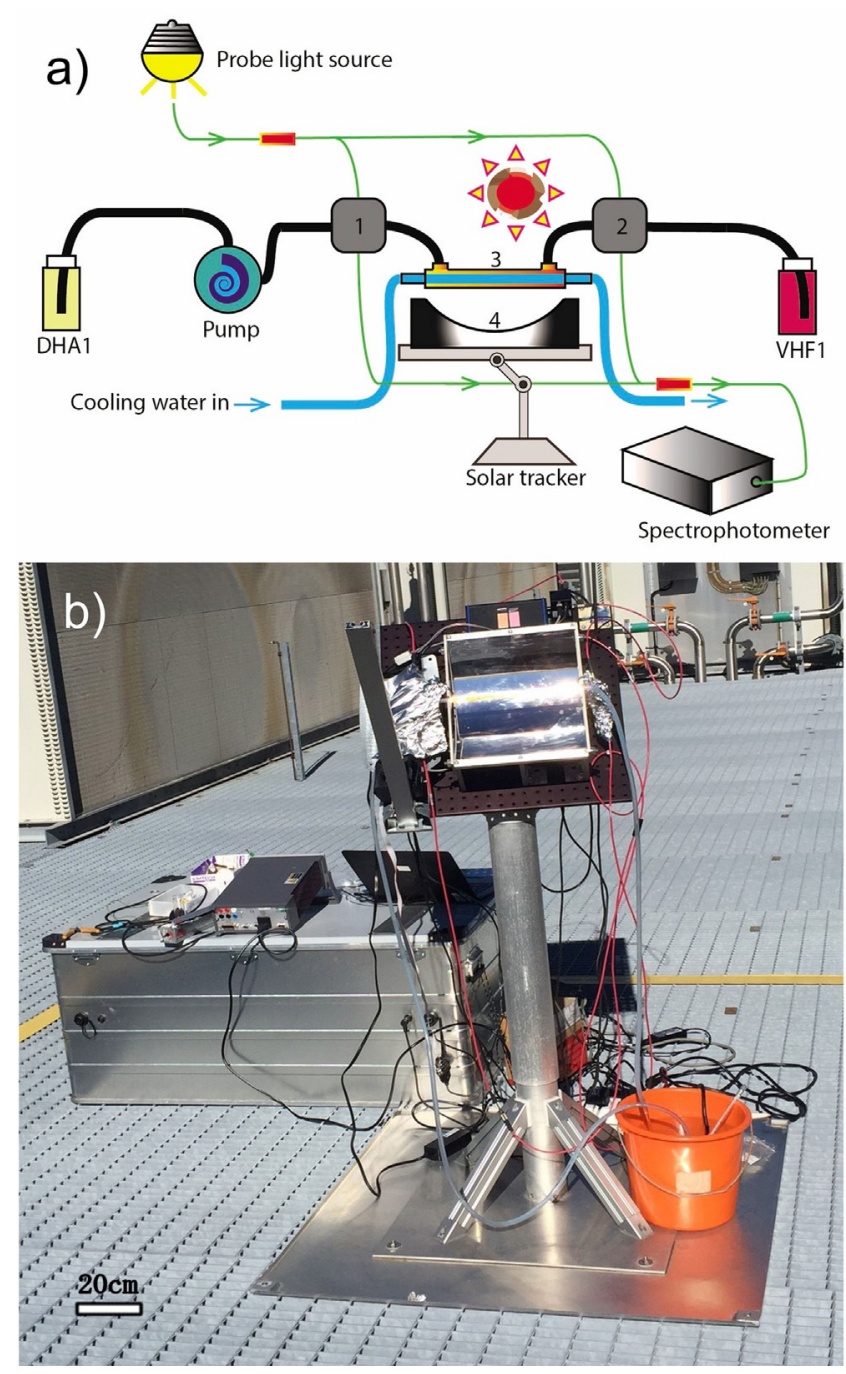

Figure 7. Outdoor parabolic concentrator setup: a) Schematic of the device. b) Actual working design. Boxes 1 and 2 represent the flow spectra detectors, as in Figure 4. Box 3 is the two-layer glass tube and box 4 shows the parabolic concentrator. Cooling water serves to keep the MOST system at sufficiently low temperature.

\section{Conclusions}

In this study, we have evaluated the DHA1/VHF1 photothermoswitch for MOST applications. Initial cycling experiments showed that a nonpolar solvent (toluene) provides a larger solubility and less degradation for long-term use than polar solvents. Moreover, the $\left[\mathrm{Cu}\left(\mathrm{CH}_{3} \mathrm{CN}\right)_{4}\right] \mathrm{PF}_{6}$-catalyzed conversion of VHF into DHA was demonstrated in a flow reactor. We also tested the solar energy storage in a laboratory-scale device, as well as, for the first time, under realistic outdoor conditions. The controllable microfluidic chip shows a good energy storage efficiency, which is very close to the theoretical estimate. Concerning the outdoor parabolic device, a need was identified for better molecular candidates with lower spectral overlap between the two isomers. Based on theory, future improvement can be focused on the enhancement of the energy storage capacity of the DHA/VHF couple $\left(\Delta H_{\text {stor }}\right)$, which is only $0.14 \mathrm{MJ} \mathrm{kg}^{-1}$ (calculated for neat compound), ${ }^{[16]}$ but, by struc- 

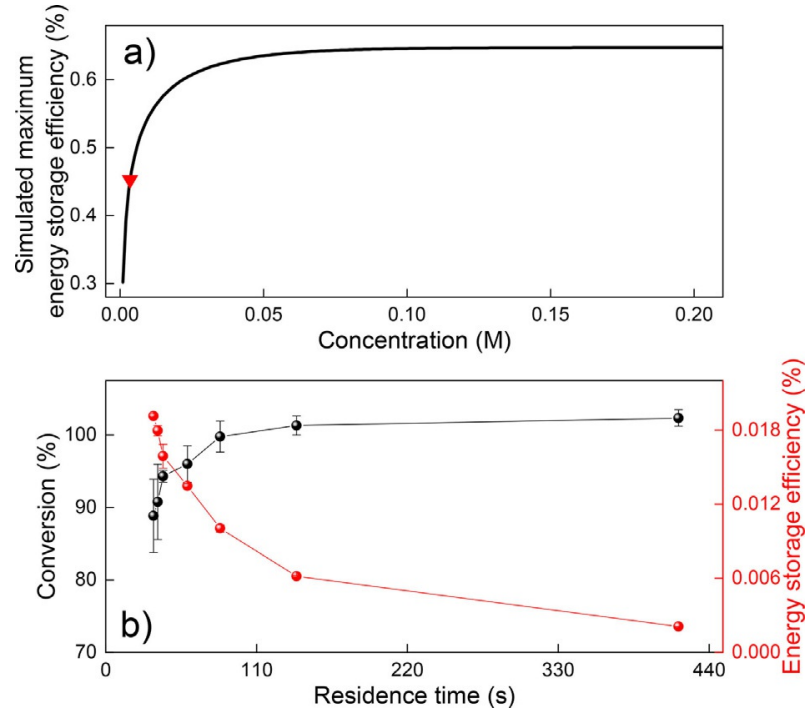

Figure 8. a) Simulated maximum energy storage efficiency as a function of concentration in a $1 \mathrm{~mm}$ path length device. b) Conversion percentage and energy storage efficiency as a function of residence time for the outdoor parabolic concentrator (in sunlight). Concentration of DHA in toluene was $3.7 \times 10^{-3} \mathrm{M}$. Data were obtained from an average of two measurements in the morning and at about midday on a cloudless sunny day in September in Gothenburg, Sweden.

tural modifications such as removing one of the two cyano groups $^{[10 b]}$ or by fusing a benzene ring to the $\mathrm{DHA}_{1}^{[10 f, g]}$ can be increased 2-4 times. However, these modifications have to date had undesired implications for the switching and stability properties, and it remains a challenge to find the optimum molecule satisfying all of these requirements. Moreover, we note that, since the use of solvents decreases the possible obtainable heat gradient, future molecular design should focus on increasing solubility, or on developing solvent-free systems. ${ }^{[6 f, g]}$ Potentially, it could be envisaged that a scale up of this system could be combined with solar water heating ${ }^{[17 a]}$ or photon up-conversion ${ }^{[6]}$ to increase the utilization of incoming photons. Finally, we envision the devices demonstrated herein to be applicable for other types of photoinduced chemical processes, such as photoinduced redox chemistry for green chemical production. ${ }^{[18]}$

\section{Experimental Section}

General: All solvents were HPLC grade. EtOH used was $99.5 \%$ in purity. Solutions of DHA1 were kept in the dark during preparation, storage, and handling until exposure to light in the testing devices (microchip or glass tube).

\section{Determination of the solubility of DHA in PhMe, MeCN, and $\mathrm{EtOH}$}

General: A modified version of a previously reported procedure was adopted. ${ }^{[13]}$ For internal standard, 1,4-dinitrobenzene (>99\% purity) was chosen. ${ }^{[19]}$ The employed DHA1 (2-phenylazulene-1, $1(8 \mathrm{a} H)$-dicarbonitrile) was recrystallized from boiling $n$-heptane (HPLC grade) to $>99 \%$ purity according to ${ }^{1} \mathrm{H}$ NMR spectroscopy. All weightings were performed on a Sartorius Extend ED2245 $d=$
$0.1 \mathrm{mg}$ analytical balance. All quantitative ${ }^{1} \mathrm{H}$ NMR (qH NMR) experiments were performed at $298 \mathrm{~K}$ on a Varian $400 / 54$ spectrometer operating at $399.94 \mathrm{MHz}$ for ${ }^{1} \mathrm{H}$. The total time occupied on the NMR instrument (including overhead for sample changes, locking, shimming, etc.) for the entire range of measurements in this investigation was roughly $9 \mathrm{~h}$. Chemical shifts are referenced to $\mathrm{CHCl}_{3}$ $(\delta=7.26$ ppm $) .{ }^{[20]}$

Solubility determination by qH NMR spectroscopy: Saturated solutions of DHA1 in the respective solvents were prepared by thorough mixing for $24 \mathrm{~h}$. Aliquots were taken, spiked with standard solution, and the resulting samples investigated by ${ }^{1} \mathrm{H}$ NMR spectroscopy under quantitative experimental conditions. Selected signals were carefully integrated to give molar ratios of the sample constituents, that is, the standard, DHA, and solvent. The molar ratios were then converted into solubility figures.

\section{Cyclability test}

A quartz cuvette with four transparent open-access sides was fixed on a magnetic stirrer, then covered by a water heating system, and inserted into a spectrophotometer (Agilent Cary 100 UV/Vis for toluene sample, Agilent Cary 4000 UV/Vis for ethanol and acetonitrile sample). Three solutions, with concentrations of around $0.6 \times$ $10^{-4} \mathrm{M}, 0.5 \times 10^{-4} \mathrm{M}$, and $0.6 \times 10^{-4} \mathrm{M}$, were prepared in toluene, acetonitrile, and ethanol, respectively. Two of the three samples were degassed by nitrogen flushing. However, due to the low boiling point of ethanol, that corresponding sample was prepared by the freeze-pump-thaw technique (ca. 5 cycles) to eliminate dissolved oxygen. $\mathrm{A} \lambda=365 \mathrm{~nm}$ collimated LED light source (Thorlabs) controlled by a custom-made LabVIEW program was used to irradiate the samples. The irradiation times were $60 \mathrm{~s}$ in toluene, $300 \mathrm{~s}$ in $\mathrm{EtOH}$, and $200 \mathrm{~s}$ in $\mathrm{MeCN}$, and the corresponding heating times were $6500 \mathrm{~s}, 1400 \mathrm{~s}$, and $2300 \mathrm{~s}$, respectively. The heating system was monitored at $60^{\circ} \mathrm{C}$ during the whole experiment with a maximum fluctuation of $+/-4{ }^{\circ} \mathrm{C}$. The recorded signal was obtained from a $\lambda=460 \mathrm{~nm}$ probe light close to the maximum absorption peak of VHF in the three solvents. All photoisomerizations and thermally induced back-conversions were monitored over at least $80 \%$ of the observed absorbance.

\section{Catalytic conversion of VHF1 to DHA1 in flow reactor}

$\left[\mathrm{Cu}\left(\mathrm{CH}_{3} \mathrm{CN}\right)_{4}\right] \mathrm{PF}_{6}(10 \mathrm{mg} ; 97 \%$ purity, Aldrich) was loaded into a Teflon tube $(1.27 \mathrm{~mm}$ inner diameter, $2.5 \mathrm{~cm}$ long; Cole-Parmer Instrument Company). Two pieces of cotton were used to prevent the copper salt from exiting the reactor. The spectrum before and after conversion was recorded by using two flow-cell spectrophotometers (Avantes, AvaSpec-2048L), placed before and after the catalytic reactor, with path lengths of around 0.03 and $0.09 \mathrm{~cm}$ for each channel individually.

\section{Microfluidic chip}

The microfluidic chip made from fused silica was acquired from Syrris Ltd. with a total volume of $62.5 \mu \mathrm{L}$, an effective exposure volume of $35.72 \mu \mathrm{L}$, irradiation surface of $5.18 \mathrm{~cm}^{2}$, and a channel depth of $85 \mu \mathrm{m}$. The fluid speed was controlled by a pump from the same source. A solution of DHA1 with concentration of $4 \times$ $10^{-3} \mathrm{M}$ was prepared and stirred in the dark over $1 \mathrm{~h}$. The path length of flow cells were determined to be around 0.06 and $0.10 \mathrm{~cm}$ for each channel individually. 


\section{Parabolic concentrator}

Into a $500 \mathrm{~mL}$ volumetric flask, DHA (475.4 mg, $1.855 \mathrm{mmol})$, and toluene (ca. $100 \mathrm{~mL}$ ) were added, after which the flask was swirled to dissolve the solids. After complete dissolution, additional toluene was added until the final volume reached $500 \mathrm{~mL}$. Finally, the flask was closed, covered with aluminum foil, and inverted several times to ensure thorough mixing, providing a DHA1 solution with $c=3.71 \times 10^{-3} \mathrm{M}$. The DHA solution was kept strictly in the dark before experiments.

A custom-made solar parabolic concentrator with net dimensions of $273 \times 327 \times 142 \mathrm{~mm}^{3}$ was put on a solar tracker, to test conversion percentage and evolution of the energy storage efficiency. ${ }^{[6]}$ A two-layer custom-designed glass tube was placed on the focusing point of the concentrator. The inner tube served to cool the system with flowing water to suppress unwanted thermal backconversion. With a volume of $5.8 \mathrm{~mL}$ and a path length of $1 \mathrm{~mm}$, the outer tube served as a flow cell for the photoswitchable compound. A fluid pump from Nortech Company was used to generate different flow speeds. After each measurement at different flow rate, pure toluene was flushed through the system until no red colour remained, after which the system was flushed with air.

The cooling water temperature increased roughly from 9 to $30^{\circ} \mathrm{C}$ during the measurements which was satisfactory for maintaining a sufficient VHF half-life. A dual-axis solar tracker setup was constructed by JTre AB. The setup featured a graphical user interface and optional automated sun tracking by a combination of geolocation and photodiode. In the current experiment, the solar tracking was adjusted manually. The solar tracker position was continuously adjusted to face the sun for each measurement. Adjustment was done manually each time, minimizing the shadow of the solar tracker's gnomon.

\section{Acknowledgements}

The University of Copenhagen and the Ragnar Söderberg Foundation are acknowledged for financial support. K.M.P., K.B., and Z.W. acknowledge the K. \& A. Wallenberg foundation and the Swedish Foundation for Strategic Research for financial support. Dr. Martyn Jevric is acknowledged for fruitful discussions.

\section{Conflict of interest}

The authors declare no conflict of interest.

Keywords: energy conversion · flow systems
photochromism $\cdot$ photolysis $\cdot$ solvent effects

[1] N. S. Lewis, D. G. Nocera, Proc. Natl. Acad. Sci. USA 2006, 103, 15729 15735.

[2] K. Moth-Poulsen, D. Ćoso, K. Börjesson, N. Vinokurov, S. K. Meier, A. Majumdar, K. P. C. Vollhardt, R. A. Segalman, Energy Environ. Sci. 2012, 5, 8534-8537.

[3] L. El Chaar, L. A. Lamont, N. El Zein, Renewable Sustainable Energy Rev. 2011, 15, 2165-2175.

[4] C. Chang, C. Yang, Y. Liu, P. Tao, C. Song, W. Shang, J. Wu, T. Deng, ACS Appl. Mater. Interfaces 2016, 8, 23412-23418.
[5] a) Z.-i. Yoshida, J. Photochem. 1985, 29, 27-40; b) A. M. Kolpak, J. C. Grossman, Nano Lett. 2011, 11, 3156-3162.

[6] a) V. Gray, A. Lennartson, P. Ratanalert, K. Börjesson, K. Moth-Poulsen Chem. Commun. 2014, 50, 5330-5332; b) M. Quant, A. Lennartson, A. Dreos, M. Kuisma, P. Erhart, K. Börjesson, K. Moth-Poulsen, Chem. Eur. J. 2016, 22, 13265-13274; c) A. Lennartson, A. Roffey, K. Moth-Poulsen, Tetrahedron Lett. 2015, 56, 1457-1465; d) T. J. Kucharski, Y. Tian, S. Akbulatov, R. Boulatov, Energy Environ. Sci. 2011, 4, 4449-4472; e) A. D. Dubonosov, V. A. Bren, V. A. Chernoivanov, Russ. Chem. Rev. 2002, 71, 917-927; f) K. Börjesson, A. Lennartson, K. Moth-Poulsen, ACS Sustainable Chem. Eng. 2013, 1, 585-590; g) K. Masutani, M. Morikawa, N. Kimizuka, Chem. Commun. 2014, 50, 15803-15806.

[7] A. Lennartson, A. Lundin, K. Börjesson, V. Gray, K. Moth-Poulsen, Dalton Trans. 2016, 45, 8740-8744.

[8] a) D. Zhitomirsky, E. Cho, J. C. Grossman, Adv. Energy Mater. 2016, 6, 1502006 ; b) T. J. Kucharski, N. Ferralis, A. M. Kolpak, J. O. Zheng, D. G. Nocera, J. C. Grossman, Nat. Chem. 2014, 6, $441-447$.

[9] A. K. Saydjari, P. Weis, S. Wu, Adv. Energy Mater. 2017, 7, 1601622.

[10] a) A. Vlasceanu, S. L. Broman, A. S. Hansen, A. B. Skov, M. Cacciarini, A. Kadziola, H. G. Kjaergaard, K. V. Mikkelsen, M. B. Nielsen, Chem. Eur. J. 2016, 22, 10796-10800; b) M. Cacciarini, A. B. Skov, M. Jevric, A.S. Hansen, J. Elm, H. G. Kjaergaard, K. V. Mikkelsen, M. B. Nielsen, Chem. Eur. J. 2015, 21, 7454-7461; c) M. Cacciarini, M. Jevric, J. Elm, A. U. Petersen, K. V. Mikkelsen, M. B. Nielsen, RSC Adv. 2016, 6, 49003-49010; d) O. Schalk, S. L. Broman, M. Å. Petersen, D. V. Khakhulin, R. Y. Brogaard, M. B. Nielsen, A. E. Boguslavskiy, A. Stolow, T. I. Sølling, J. Phys. Chem. A 2013, 117, 3340-3347; e) M. Cacciarini, A. Vlasceanu, M. Jevric, M. B. Nielsen, Chem. Commun. 2017, 53, 5874-5877; f) A. B. Skov, S. L. Broman, A. S. Gertsen, J. Elm, M. Jevric, M. Cacciarini, A. Kadziola, K. V. Mikkelsen, M. B. Nielsen, Chem. Eur. J. 2016, 22, 14567-14575; g) A. B. Skov, J. F. Petersen, J. Elm, B. N. Frandsen, M. Santella, M. D. Kilde, H. G. Kjaergaard, K. V. Mikkelsen, M. B. Nielsen, ChemPhotoChem 2017, 1, $206-212$.

[11] S. L. Broman, M. Jevric, A. D. Bond, M. B. Nielsen, J. Org. Chem. 2014, 79, $41-64$.

[12] S. L. Broman, S. L. Brand, C. R. Parker, M. Å. Petersen, C. G. Tortzen, A. Kadziola, K. Kilsaa, M. B. Nielsen, ARKIVOC 2011, 51-67.

[13] M. Lin, M. Tesconi, M. Tischler, Int. J. Pharm. 2009, 369, 47-52.

[14] H. Goerner, C. Fischer, S. Gierisch, J. Daub, J. Phys. Chem. 1993, 97, 4110-4117.

[15] M. Å. Petersen, K. Kilså, A. Kadziola, M. B. Nielsen, Eur. J. Org. Chem. 2007, 1415-1418.

[16] S. T. Olsen, J. Elm, F. E. Storm, A. N. Gejl, A. S. Hansen, M. H. Hansen, J. R. Nikolajsen, M. B. Nielsen, H. G. Kjaergaard, K. V. Mikkelsen, J. Phys. Chem. A 2015, 119, 896-904.

[17] a) A. Dreos, K. Borjesson, Z. Wang, A. Roffey, Z. Norwood, D. Kushnir, K. Moth-Poulsen, Energy Environ. Sci. 2017, 10, 728-734; b) K. Jorner, A. Dreos, R. Emanuelsson, O. E. Bakouri, I. F. Galván, A. Roffey, K. Börjesson, F. Feixas, R. Lindh, B. Zietz, K. Moth-Poulsen, H. Ottosson, J. Mater. Chem. A 2017, 5, 12369-12378.

[18] D. Cambié, F. Zhao, V. Hessel, M. G. Debije, T. Noel, Angew. Chem. Int. Ed. 2017, 56, 1159; Angew. Chem. 2017, 129, 1179.

[19] T. Rundlöf, M. Mathiasson, S. Bekiroglu, B. Hakkarainen, T. Bowden, T. Arvidsson, J. Pharm. Biomed. Anal. 2010, 52, 645-651.

[20] a) G. R. Fulmer, A. J. M. Miller, N. H. Sherden, H. E. Gottlieb, A. Nudelman, B. M. Stoltz, J. E. Bercaw, K. I. Goldberg, Organometallics 2010, 29, 2176 2179 ; b) H. E. Gottlieb, V. Kotlyar, A. Nudelman, J. Org. Chem. 1997, 62, $7512-7515$.

Manuscript received: April 22, 2017

Revised manuscript received: June 7, 2017

Accepted manuscript online: June 23, 2017

Version of record online: July 19, 2017 